\title{
PENGARUH TERAPI MENULIS PENGALAMAN EMOSIONAL TERHADAP TINGKAT DEPRESI LANSIA DI PANTI WREDA DARMA BAKTI KASIHSURAKARTA
}

\author{
Tunjung Sri Yulianti ${ }^{1}$, Ria Kurniawati ${ }^{2}$
}

\begin{abstract}
Background : a person in the elderly will experience a failure to maintain a balance of physiological stress conditions, resulting in increased susceptibility to depression. Socioeconomic changes and social values of society, family system shift from extended family to nuclear family, industrialization culture with independent character and individualist consider elderly as "trouble maker" and become burden. This results in the tendency of the elderly to be excluded and, not getting treatment, so many choose to place it in elderly homes. This condition will of course affect the incidence of depression in the elderly. To overcome depression can be done various therapies, one of which is writing therapy, the therapy that does not give priority to physical complaints but the enlightenment of the soul through the release of emotions. Expressive writing is a form of writing to release and explore the deepest traumatic emotions and thoughts that make the sufferer feel an inner wound. Purpose of the study: to determine the effect of writing therapy emotional experiences on the level of depression in the elderly.

Methods : quasy experimental research. Data analysis using t test formula with SPSS program series 18 . Subjects : elderly living in a nursing home.

Results: the significance value of $t$ test ( 2 tailed) is 0.015 .

Conclusion : that writing therapy can reduce the level of depression in the elderly.
\end{abstract}

Keywords: Writing Therapy, Elderly Depression

\section{PENDAHULUAN}

Seseorang yang berada pada periode lanjut usia akan mengalami kegagalan untuk mempertahankan keseimbangan terhadap kondisi stress fisiologis, sehingga kerentanan orang lanjut usia terhadap gangguan depresi meningkat. Depresi adalah gangguan alam perasaan atau mood yang ditandai dengan kemurungan dan kesedihan yang mendalam dan berkelanjutan sehingga hilangnya kegairahan hidup, perilaku dapat terganggu tetapi dalam batas-batas normal (Hawari, 2008). Menurut (Aspiani, 2014) depresi merupakan masa terganggunya fungsi manusia yang berkaitan dengan alam perasaan sedih dan gejala penyertanya, termasuk mengubah pola tidur dan nafsu makan, psikomotor,kelelahan, konsentrasi, rasa putus asa dan tidak berdaya. Depresi pada lansia merupakan permasalahan kesehatan jiwa (mental health) yang serius dan komplek, tidak hanya dikarenakan aging process tetapi juga faktor lain yang sangat terkait. Persentase penduduk lanjut usia di Jawa Tengah telah mencapai $11.7 \%$ dengan penduduk usia lanjut wanita lebih tinggi dibandingkan laki-laki dan diperkirakan meningkat pada tahun 2025. Peningkatan penduduk lanjut usia ini akan meningkatkan prevalensi lanjut usia dengan gejala atau gangguan depresi.

Menurut Aspiani (2014) perubahan sosial ekonomi dan nilai sosial masyarakat, mengakibatkan kecenderungan lansia tersisihkan dan terbengkalai, tidak mendapatkan perawatan serta banyak yang memilih untuk menempatkannya di panti lansia. Pergeseran sistem keluarga dari extended family ke nuclear family akibat industrialisasi dan urbanisasi 
mengakibatkan lansia terpinggirkan. Budaya industrialisasi dengan sifat mandiri dan individualis menganggap lansia sebagai "trouble maker" dan menjadi beban sehingga langkah penyelesaiannya dengan menitipkan di panti. Kondisi ini tentu saja akan berpengaruh pada kejadian depresi pada lansia. Penelitian yang dilakukan oleh Sari, Arneliwati dan Utami (2015) ditemukan hasil lansia yang tinggal di panti mempunyai tingkat depresi lebih tinggi daripada yang tinggal bersama keluarga.

Untuk mengatasi depresi dapat dilakukan berbagai terapi, salah satunya adalah terapi menulis, yaitu terapi yang tidak mengutamakan keluhan fisik melainkan pencerahan jiwa melalui pelepasan emosi dan bisa dilakukan secara bersamasama dengan dibimbing tutor penulis kreatif atau terapis. Emosi merupakan sebuah pengalaman rasa, saat merasakan adanya emosi, seseorang tidak sekedar memikirkannya. Ketika seseorang mengatakan atau melakukan sesuatu yang secara pribadi penting, maka emosi dapat meresponnya, biasanya diikuti dengan pikiran yang ada hubungannya dengan perkataan tersebut, perubahan psikis, dan juga hasrat untuk melakukan sesuatu. Contoh, jika orang itu kehilangan kekuasaan dan kekuatan (powerless) artinya sesuatu yang dimiliki dan dicintai kini telah tiada (lost off love object). Dampak nya adalah terganggunya keseimbangan mental emosional dengan munculnya berbagai keluhan fisik (somatic), kecemasan dan depresi (Hawari, 2008). Emosi bukan hanya soal kemarahan melainkan emosi juga dapat berubah menjadi depresi. Writing for Therapy (WFT) atau menulis untuk terapi bertujuan untuk pencerahan jiwa melalui pelepasan atau kegiatan menulis. Siapa saja berhak melakukannya tanpa pandang bulu. Menulis ekspresif merupakan bentuk tulisan untuk melepaskan dan mengeksplorasi emosi dan pikiran yang terdalam paling traumatis yang membuat penderitanya merasa luka batin. (Pranoto, 2015 ).

Hasil wawancara di Panti Wreda Darma Bakti Kasih Surakarta diperoleh data bahwa beberapa lansia diketahui memiliki ciri-ciri lansia yang mengalami depresi yaitu menyatakan merasa putus asa, tidak berguna, tidak mau mengikuti kegiatan-kegiatan yang ada, bahkan beberapa diantaranya menyatakan ingin mati saja. Selama ini tindakan yang dilakukan oleh petugas panti adalah mendengarkan dan memberi nasihat atau motivasi kepada lansia tersebut dan belum pernah dilakukan tindakan-tindakan psikoterapi yang lain.

\section{TUJUAN PENELITIAN}

Mengetahui pengaruh terapi menulis pengalaman emosional terhadap tingkat depresi pada Lansia di Panti Wreda Darma Bakti Kasih Surakarta.

\section{DESAIN PENELITIAN}

Penelitian ini merupakan jenis penelitian quasi experimental, untuk mengetahui apakah ada pengaruh teknik terapi menulis pengalaman emosional terhadap tingkat depresi.

\section{POPULASI, SAMPEL, DAN TEHNIK SAMPLING}

Populasi pada penelitian ini adalah seluruh lansia yang tinggal di Panti Wreda Darma Bakti Kasih Surakarta berjumlah 60 orang. Menggunakan teknik purposif sampling diperoleh responden sebanyak 17 lansia dengan kriteria inklusi :

1. Bersedia menjadi responden

2. Lansia yang bisa membaca dan menulis dengan lancar

3. Lansia yang bisa diajak berkomunikasi verbal dengan baik 
HASIL PENELITIAN

Tabel 1.

Karakteristik Responden

\begin{tabular}{cccc}
\hline Variabel & Kategori & $\mathrm{f}$ & $\%$ \\
Jenis & Laki-laki & 5 & 29.4 \\
Kelamin & Perempuan & 12 & 70.6 \\
& & & \\
Tingkat & SD & 1 & 5.9 \\
Pendidikan & SMP/SKP & 6 & 35.3 \\
& SMA & 7 & 41.2 \\
& PT & 3 & 17.6 \\
Adanya & Ada & 4 & 23.5 \\
Pasangan & Tidak Ada & 13 & 76.5 \\
& Ada & 10 & 58.8 \\
Adanya & Tidak Ada & 7 & 41.2 \\
Penyakit & Ada & 14 & 82.4 \\
Adanya & Tidak Ada & 3 & 17.6 \\
Keluarga & & & \\
Pertemuan & Tidak Pernah & 0 & 0 \\
dengan & Jarang & 8 & 57.1 \\
Keluarga & Sering & 6 & 42.9 \\
\hline
\end{tabular}

Dari tabel di atas diperoleh informasi bahwa mayoritas responden berjenis kelamin perempuan yaitu 12 orang (70.6\%). Tingkat pendidikan responden mayoritas SMA yaitu 7 orang (41.2\%). Sebagian besar responden tidak mempunyai pasangan hidup yaitu 13 orang $(76.5 \%)$. Sebagian besar responden memiliki penyakit yaitu 10 orang (58.8\%). Mayoritas responden memiliki keluarga yaitu 14 orang (82.4\%) tetapi jarang bertemu dengan keluarga yaitu 8 orang $(57.1 \%)$.

Tabel 2.

Depresi Lansia

Sebelum Terapi Menulis

\begin{tabular}{cccc}
\hline No & $\begin{array}{c}\text { Tingkat } \\
\text { Depresi }\end{array}$ & $f$ & $\%$ \\
\hline 1 & Tidak Ada & 9 & 52.9 \\
2 & Ringan & 4 & 23.5 \\
3 & Sedang & 4 & 23.5 \\
\hline & Jumlah & 17 & 100 \\
\hline
\end{tabular}

Dari tabel di atas dapat diketahui bahwa sebagian besar responden berada pada tingkat tidak ada depresi yaitu 9 orang (52.9\%). Rata-rata tingkat depresi lansia sebelum dilakukan terapi menulis berada pada kategori depresi ringan (Mean sebesar 11.23).

Tabel 3.

Depresi Lansia Sesudah Terapi Menulis

\begin{tabular}{cccc}
\hline No & Tingkat Depresi & $\mathrm{f}$ & $\%$ \\
\hline 1 & Tidak Ada & 14 & 82.4 \\
2 & Ringan & 3 & 17.6 \\
3 & Sedang & 0 & 0 \\
\hline & Jumlah & 17 & 100 \\
\hline
\end{tabular}

Dari tabel di atas dapat diketahui bahwa sebagian besar responden yaitu 14 orang (82.4\%) berada pada tingkat tidak ada depresi. Rata-rata tingkat depresi lansia setelah dilakukan terapi menulis berada pada kategori tidak ada depresi (Mean sebesar 7.17).

Tabel 4.

Perbedaan Tingkat Depresi Lansia Sebelum dan Sesudah Terapi

\begin{tabular}{cccccc}
\hline $\begin{array}{c}\text { Tingkat } \\
\text { Depresi }\end{array}$ & $\begin{array}{c}\text { Sebe } \\
\text { lum }\end{array}$ & $\begin{array}{c}\text { Sesu } \\
\text { dah }\end{array}$ & $\%$ & $\mathrm{t}$ \\
\hline Tidak ada & 9 & 53 & 14 & 82.4 & 0.015 \\
Ringan & 4 & 23.5 & 3 & 17.6 & \\
Sedang & 4 & 23.5 & 0 & 0 & \\
\hline Rata-rata & 11.23 & & 7.17 & & \\
\hline
\end{tabular}

Tabel di atas menunjukkan perbedaaan tingkat depresi lansia sebelum dan sesudah dilakukan terapi menulis, melalui uji perbedaan dengan Paired Samples t-test, nilai significancy dari t-test (2-tailed) yang diperoleh adalah 0.015. Dengan demikian dapat diketahui bahwa ada perbedaan yang signifikan tingkat depresi antara lansia sebelum dan sesudah dilakukan 
tindakan terapi menulis pengalaman emosional. Sebelum dilakukan terapi menulis rata-rata depresi lansia berada pada tingkat ringan sedang sedangkan setelah dilakukan terapi menulis rata-rata lansia berada pada tingkat tidak ada depresi.

Tabel 5.

Respon Verbal Lansia Sesudah Terapi Menulis

\begin{tabular}{clc}
\hline No & \multicolumn{1}{c}{ Respon Verbal } & $f$ \\
\hline 1 & Lega dan tenang & 13 \\
2 & $\begin{array}{l}\text { Bebas mengungkapkan } \\
\text { perasaan }\end{array}$ & 7 \\
3 & $\begin{array}{l}\text { Hati longgar dan pusing } \\
\text { berkurang }\end{array}$ & 5 \\
\hline
\end{tabular}

\section{PEMBAHASAN}

1. Tingkat Depresi pada Lansia Sebelum Diberikan Tindakan Terapi Menulis.

Rata-rata responden berada pada kategori depresi ringan dengan nilai Mean (11.23). Kondisi tersebut bisa dipahami karena beberapa perubahan akibat proses menua memberikan dampak pada psikologis lansia. Dikuatkan oleh paparan Nugroho (2008) bahwa menua bukanlah suatu penyakit, tetapi merupakan proses yang berangsur-angsur mengakibatkan perubahan yang kumulatif. Lansia yang tidak bisa menerima perubahan yang terkait dengan proses menua yang dialaminya tersebut menyebabkan perubahan psikologis dan sosial. Seperti paparan Aspiani (2014) yang menyatakan bahwa depresi pada lansia adalah dampak negatif kejadian penurunan fungsi tubuh dan perubahan yang terjadi terutama perubahan psikososial dan kehilangan kebutuhan afeksional misalnya kehilangan orang yang dicintai, pekerjaan, jabatan dan sejenisnya.
Apabila dicermati lebih lanjut ditemukan hasil bahwa 8 lansia jarang di jenguk dan bertemu dengan keluarga. Kondisi ini dimungkinkan akan membuat lansia merasa kehilangan atau terpisah dari orang yang dicintai dan merasa terpinggirkan. $\mathrm{Hal}$ tersebut dikuatkan oleh Aspiani (2014) bahwa perubahan sosial ekonomi dan nilai sosial masyarakat, mengakibatkan kecenderungan lansia tersisihkan dan terbengkalai, tidak mendapatkan perawatan serta banyak yang memilih untuk menempatkannya di panti lansia. Pergeseran sistem keluarga dari extended family ke nuclear family akibat industrialisasi dan urbanisasi mengakibatkan lansia terpinggirkan.

Beberapa hal yang menyebabkan depresi pada lansia yang tinggal di panti wreda juga dipaparkan oleh Aspiani (2014) yaitu : 1) faktor psikologis. Motivasi masuk ke panti wreda sangat penting bagi lansia untuk menentukan tujuan hidup dan apa yang ingin dicapainya dalam kehidupan di panti. Rasa tidak berdaya atau kurang percaya diri serta selalu menganggap bahwa hidupnya gagal karena harus menghabiskan sisa hidupnya jauh dari orang yang dicintainya mengakibatkan lansia memandang masa depannya suram dan selalu menyesali diri. 2) Faktor psikososial. Kunjungan keluarga yang kurang, berkurangnya interaksi dan dukungan sosial menyebabkan penyesuaian diri yang negatif, merasa tidak berguna dan disingkirkan. 3) Faktor budaya. Budaya industrialisasi dengan sifat mandiri dan individualis menganggap lansia sebagai "trouble maker" dan menjadi beban sehingga langkah penyelesaianya 
menitipkan di panti. Akibatnya bagi lansia memperburuk kondisi psikologisnya dan mempengaruhi kesehatannya. Kondisi - kondisi ini tentu saja akan berpengaruh pada kejadian depresi pada lansia.

Senada dengan hal tersebut, penelitian yang dilakukan oleh Sari, Arneliwati dan Utami (2015) juga menemukan hasil bahwa lansia yang tinggal di panti mempunyai tingkat depresi lebih tinggi daripada yang tinggal bersama keluarga. Keberadaan lansia di antara keluarga bisa meningkatkan kepercayaan diri lansia karena mereka merasa masih bisa berguna bagi hidupnya sendiri maupun keluarga. Keluarga yang bisa diajak berkomunikasi memungkinkan lansia tidak mengalami kesepian, tersisihkan dan terbengkalai sehingga menurunkan resiko terjadinya masalah kesehatan jiwa pada lansia. Hal ini sesuai dengan hasil penelitian yang dilakukan oleh Siboro dan Rusdi (2012) yang menunjukkan hasil bahwa pola komunikasi keluarga yang fungsional semakin menurunkan tingkat depresi pada lansia.

Terkait dengan kondisi kesehatan, dari data diketahui 10 orang lansia (58.8\%) sering mengalami gangguan kesehatan atau mempunyai penyakit terutama penyakit degeneratif yang menyebabkan lansia merasa kehilangan fungsi tubuhnya. Sedangkan dari data pasangan hidup, sebagian besar responden $(76.5 \%)$ sudah tidak memiliki pasangan hidup. Kondisi-kondisi seperti ini beresiko meningkatkan kejadian depresi pada lansia. Hal tersebut dikuatkan oleh paparan dari Ibrahim $\left(2011^{b}\right) \quad$ yang menyatakan bahwa penyakit kronis (menahun), dapat menimbulkan depresi. Penyakit jantung, hipertensi, penyakit gula, penyakit hati akan menjalar dalam gangguan bentuk depresi. Sedangkan menurut Maryam, et al. (2008), faktor resiko terjadinya masalah kesehatan jiwa pada lansia antara lain : kesehatan fisik yang buruk dan perpisahan dengan pasangan.

2. Pengaruh Terapi Menulis Pengalaman Emosional terhadap Tingkat Depresi

Skore rata-rata responden setelah dilakukan terapi menulis berada pada kategori tidak ada depresi (Mean 7,17). Lansia yang sebelum dilakukan terapi menulis berada pada kategori depresi sedang menurun skore nya menjadi ringan dan tidak ada depresi.

Melalui uji perbedaan dengan Paired Samples T-Test, nilai significancy dari t-test (2-tailed) yang diperoleh adalah 0.015 . Dengan demikian dapat diketahui bahwa ada perbedaan yang signifikan tingkat depresi antara lansia sebelum dan sesudah dilakukan tindakan terapi menulis pengalaman emosional. Ada penurunan tingkat depresi setelah dilakukan terapi menulis. Hal ini berarti bahwa terapi menulis yang diberikan saat intervensi berpengaruh pada tingkat depresi responden. Menulis memberikan efek terapi, yaitu menurunkan tingkat depresi pada saat responden mengungkapkan emosi dan perasaannya melalui tulisan.

Ibrahim $\left(2011^{a}\right)$ memaparkan bahwa dasar penatalaksanaan depresi adalah dengan meringankan penderitaan dan membantu pasien mengenali dan mengutarakan kegelisahannya. Dalam penelitian ini, lansia diberikan terapi menulis pengalaman emosional untuk membantu mengungkapkan 
pikiran, perasaan dan hal-hal yang membuat gelisah dan berkontribusi dalam kejadian depresi.

Hasil penelitian ini sesuai dengan penelitian Sulistiowati dan Hasanat (2011) yang menunjukkan hasil adanya penurunan depresi setelah subjek menuliskan pengalaman emosional pada buku harian. Dari analisa kualitatif diketahui dinamika subjek dalam menghadapi kejadian-kejadian menekan dan terapi menulis pengalaman emosional merupakan sarana bantu diri yang efektif untuk menurunkan depresi pada mahasiswa tahun pertama.

Untuk mengatasi depresi dapat dilakukan berbagai terapi, salah satunya adalah terapi menulis, yaitu terapi yang tidak mengutamakan keluhan fisik melainkan pencerahan jiwa melalui pelepasan emosi. Writing for Therapy (WFT) atau menulis untuk terapi bertujuan untuk pencerahan jiwa melalui pelepasan atau kegiatan menulis (Pranoto, 2015). Hal serupa juga dipaparkan oleh Stanley dan Beare (2007) bahwa salah satu penatalaksanaan depresi pada lansia adalah dengan melakukan pencegahan tersier yaitu modalitas kelompok. Salah satu terapi yang bisa dilakukan adalah terapi yang mendorong ingatan atau tinjauan hidup yang akan membantu menyelesaikan masalah lama dan meningkatkan identifikasi pencapaian di masa lalu, yang dituangkan dalam tulisan. Lansia akan mendapatkan keuntungan dari menulis pengalaman hidupnya.

Paparan di atas menguatkan hasil penelitian ini, dimana dari hasil wawancara diperoleh data 13 responden mengatakan bahwa setelah menuliskan apa yang dirasakan responden menjadi lega dan lebih tenang karena sudah mengungkapkan hal yang dipikirkan dan dirasakan. Salah satu lansia menyatakan bahwa setelah menulis, merasa lebih nyaman karena hal yang selama ini sulit diceritakan kepada orang lain sudah diungkapkan melalui tulisan di bukunya. Hal ini sesuai dengan paparan Pranoto (2015) yang menyatakan bahwa kegiatan terapi menulis ekspresif adalah bentuk tulisan untuk melepas dan mengeksplorasikan emosi dan pikiran yang terdalam, paling traumatis yang membuat penderitanya merasakan luka batin. Terapi menulis untuk semua orang, tanpa mengenal usia dan strata pendidikan maupun kelas ekonomi. Dengan kata lain siapa saja berhak melakukannya tanpa pandang bulu. Hal serupa juga bisa diterapkan untuk kaum lansia yang mengalami stress, depresi maupun trauma.

Responden lain (7 orang) mengungkapkan pada saat menulis di buku responden merasa bisa bebas meluapkan apa yang dirasakan sehingga rasa jengkelnya semakin berkurang. Kondisi ini senada dengan hasil penelitian Fikri (2012) yang memperlihatkan bahwa menulis pengalaman emosional dalam terapi ekspresif mampu untuk menurunkan emosi marah pada remaja. Selain itu, terapi menulis dapat dijadikan sebagai salah satu sarana katarsis dan media self-help bagi seseorang untuk mengekspresikan emosi dan perasaan marahnya. Sedangkan penelitian kualitatif yang dilakukan oleh Muthoharoh (2013) diperoleh hasil subjek melakukan dua hal dalam proses terapi menulis ekspresif, yaitu: mengungkapkan peristiwa 
traumatis dan emosi terdalam terkait peristiwa tersebut. Proses tersebut kemudian dapat membantu memulihkan kondisi psikosomatik yang dialami subjek. Hasil-hasil penelitian di atas dikuatkan oleh paparan Pranoto (2015) bahwa terapi menulis bertujuan untuk melepaskan tekanan batin dan sekaligus menyenangkan hati. Tulisan tangan tidak hanya meningkatkan motorik syaraf syaraf pergelangan tangan tapi ujung pena saat digoreskan getarannya merangsang kerja otak kiri dan otak kanan seimbang. Efeknya memperaktif memori. Dengan aktifnya memori, seseorang akan menjadi rileks, kreatif dan produktif karena pikirannya jernih. Secara fisik, saat menulis dengan tangan seseorang dapat memposisikan diri senyaman mungkin sesuai kehendak hati. Pada saat akan menggoreskan huruf di atas kertas, mata pena bergetar dan itu akan memperlancar peredaran darah penulis. Dampaknya ketegangan (tense) jiwa akan tereduksi oleh katakata yang dicurahkan melalui tulisan.

Sedangkan 5 responden mengatakan setelah menulis beberapa kali hatinya lebih longgar dan rasa pusing kepalanya sudah mulai berkurang. Hal tersebut sesuai dengan paparan Pranoto (2015), yaitu manfaat terapi menulis antara lain : untuk melepaskan dan mengeksplorasikan emosi serta pikiran yang terdalam, melepas tekanan batin sekaligus menyenangkan hati serta mencerahkan jiwa, dan merupakan kegiatan yang sangat positif untuk mereduksi trauma. Ketidakstabilan emosi mengakibatkan kerapuhan organ tubuh. Stress tingkat ringan hingga berat dapat mengganggu kerja jantung dan otak. Hal tersebut dapat diatasi dengan mengubah emosi negatif menjadi positif melalui kata-kata yang diucapkan maupun ditulis.

Dengan demikian berdasarkan hasil penelitian yang telah dilakukan, didukung dengan hasil-hasil penelitian terdahulu dan paparan teori yang terkait, maka dapat disimpulkan bahwa secara keseluruhan terapi menulis mampu menurunkan tingkat depresi pada lansia. Artinya dalam penelitian ini terdapat efek terapi, yaitu pengurangan tekanan atau penurunan emosi pada responden ketika mengungkapkan emosi dan perasaannya melalui tulisan.

\section{KESIMPULAN}

Hasil penelitian menunjukkan bahwa ada pengaruh tindakan terapi menulis pengalaman emosional terhadap penurunan tingkat depresi pada lansia yang ditunjukkan dengan nilai significancy dari t-test (2-tailed) yang diperoleh yaitu 0,015 .

\section{SARAN}

1. Bagi lansia yang masih bisa membaca dan menulis disarankan untuk tetap menulis semua hal yang dirasakan atau dipikirkan agar beban jiwanya menjadi lebih lega dan tidak mengalami depresi.

2. Bagi pengelola panti disarankan untuk memfasilitasi terapi menulis pada lansia penghuni panti, memantau dan mengevaluasi hasilnya.

3. Disarankan pada keluarga untuk lebih sering bertemu (menjenguk) dan berkomunikasi dengan lansia yang tinggal di panti agar perasaan tersingkirkan dan terabaikan 
yang bisa berkontribusi pada kejadian depresi bisa berkurang.

\section{DAFTAR PUSTAKA}

Aspiani, R. Y. 2014. Buku Ajar Asuhan Keperawatan Gerontik. Jilid 1. EGC, Jakarta.

Fikri, H. T. 2012. Pengaruh Menulis Pengalaman Emosional dalam Terapi Ekspresif Terhadap Emosi Marah pada Remaja. Skripsi. Universitas Putra Indonesia YPTK. Sumatra Barat.

Hawari, H. D. 2008. Manajemen Stres Cemas dan Depresi. Fakultas Kedokteran Universitas Indonesia, Jakarta.

Ibrahim, A. S. 2011 a . Depresi Aku Ingin Mati. Jelajah Nusantara, Tanggerang.

- 2011'. Gangguan Akan Perasaan. Jelajah Nusantara, Tanggerang.

Maryam, S., et al. 2008. Mengenal Usia Lanjut dan Perawatannya. Salemba Medika, Jakarta.

Muthoharoh, H. 2012. Studi tentang Terapi Menulis Ekspresif untuk Menurunkan Stres pada Penderita Gangguan Psikosomatik. Thesis, Universitas Islam Negeri Maulana Malik Ibrahim, Malang.

Nugroho, W. 2008. Keperawatan Gerontik dan Geriatrik. ed. 3. EGC, Jakarta.

Pranoto, N. 2015. Writing for Theraphy. Yayasan Pustaka Obor Indonesia, Jakarta.
Sari, R., Arneliawati dan S. Utami. 2015. Perbedaan Tingkat Depresi antara Lansia yang Tinggal di PSTW dengan Lansia yang Tinggal di Tengah Keluarga. http://jom.unri.ac.id/index.php/JO MPSIK/article/view/8318. Diakses tanggal 14 April 2016.

Siboro, E. N. dan I. Rusdi. 2012. Pola Komunikasi Keluarga Dan Tingkat Depresi Lansia Di Kelurahan Padang Bulan Medan. http://download.portalgaruda.org/ article. php?article $=59065 \& \mathrm{val}=41$ 32. Diakses tanggal 14 April 2016.

Stanley M. dan P. G. Beare. 2007. Buku Ajar Keperawatan Gerontik. Ed. II. Alih bahasa Nety Juniarti dan Sari Kurniasih. EGC, Jakarta.

Sulistiowati, G. T. dan N. U. I. Hasanat. 2011. Pengaruh Terapi Menulis Pengalaman Emosional terhadap Penurunan Depresi pada Mahasiswa Tahun Pertama. Skripsi. Fakultas Psikologi Universitas Gadjah Mada, Yogyakarta.

\footnotetext{
${ }^{1}$ Dosen Akper Panti Kosala

Surakarta

${ }^{2}$ Mahasiswa Akper Panti Kosala

Surakarta
} 